\title{
22. GEOTECHNICAL PROPERTIES OF SEDIMENTS IN A CARBONATE-SLOPE ENVIRONMENT: OCEAN DRILLING PROGRAM SITE 630, NORTHERN LITTLE BAHAMA BANK1
}

\author{
Dawn Lavoie ${ }^{2}$
}

\begin{abstract}
Three holes were cored at Site 630 during Leg 101 of the Ocean Drilling Program. Whole-round samples were obtained for geotechnical analyses from Hole 630B. Consolidation studies, which relate changes in the coefficients of consolidation, compressibility, and permeability to the overburden pressure, indicate that sediments recovered to $79.4 \mathrm{mbsf}$ (meters below seafloor) are not significantly consolidated. This may be a function of total carbonate content, mineralogy, and type of carbonate constituents. The lower total porosity and permeability of Section 101-630B-2H-5 relative to 101-630B-5H-6 and 101-630B-9H-6 are explained in terms of effective fluid flow, total calcium carbonate content, and type of constituents present.

Results from triaxial shear testing and direct shear testing indicate that Section 101-630B-2H-5 has a higher degree of cohesion and a higher angle of internal friction $(\phi)$ than sediment recovered deeper in the section, although angles of internal friction from all three samples are lower than typical angles measured from deep-sea foraminiferal ooze. Attempts to compare triaxial shear results qualitatively with measurements of undrained vane shear strength from Hole $630 \mathrm{~A}$ suggest that the latter may be meaningless if taken from sediments dependent on overburden pressure to maintain strength.

Calculations based on consolidated and drained shear strength suggest that if the sediment column is homogeneous, the slope will be stable to $14^{\circ}$ of inclination. If the inhomogeneities in the section, such as the turbidite layers known to be present, are weaker than the sediments tested, then the stable slope inclination may be less than that calculated. This is substantiated by the abundance of seismic evidence for slumping, sliding, and imbricate thrusting on this gentle ( $\left(2^{\circ}-\right.$ $3^{\circ}$ ) slope.
\end{abstract}

\section{INTRODUCTION}

Sediment shear strength and slope stability are related to the physical properties of sediments. Soil mechanics principles and consolidation and triaxial shear testing can therefore be used to study the depositional characteristics of slope carbonate sediments. From these analyses, consolidation characteristics, including compressibility and permeability, and shear-strength characteristics can be determined. Drilling at Site 630 , north of Little Bahama Bank, investigated changes in the shear strength of carbonate sediments as a function of burial depth and related results to shipboard physical-property measurements of these same sediments. An expected result is that an increase in consolidated, drained, shear strength would correlate with increased undrained shear strength and with increased shear velocity. An unexpected result is that the total percentage of calcium carbonate and the specific types of grain and matrix material are as important as overburden pressure on shear strength and consolidation characteristics of these carbonate sediments.

\section{STRATIGRAPHY}

Site 630 , the shallowest of a three-site transect north of Little Bahama Bank, was cored at a water depth of $807 \mathrm{~m}$ (corrected) (Fig. 1). A major objective was to sample a complete sequence of periplatform ooze of the Little Bahama Bank transect in order to study sediment transport between two major gullies on a gentle $\left(2^{\circ}-3^{\circ}\right)$ accretionary slope (Austin, Schlager, et al., 1986). Hole 630B duplicated the upper part of the section at Site 630 so that whole-round geotechnical samples could be obtained. The geotechnical analyses were intended to character-

\footnotetext{
${ }^{1}$ Austin, J. A., Jr., Schlager, W., et al., Proc. ODP, Sci. Results, 101: College Station, TX (Ocean Drilling Program).

2 Seafloor Geosciences Division, U.S. Naval Ocean Research and Development Activity (NORDA), NSTL, MS 39529.
}

ize the change in consolidation and shear-strength characteristics of carbonate periplatform ooze with increasing overburden stress.

After shipboard study of smear slides, two major stratigraphic units in Hole 630A were identified (Austin, Schlager, et al., 1986). Unit I ( $0-146$ mbsf) consisted of about $90 \%$ periplatform ooze and $10 \%$ turbidite layers (packstones). One whole-round sample was recovered from Hole 630B at a depth that correlates with Subunit $1 \mathrm{~A}$ and two from depths that presumably correlate with Subunit 1B (Table 1). However, both measured index properties and the lack of aragonite (Table 2) indicate that Section 101-630B-9H-6, recovered from 79.4 to $79.8 \mathrm{mbsf}$, is more typical of sediments recovered from Subunit $1 \mathrm{C}$.

Shipboard calcium carbonate measurements indicate that the upper $30 \mathrm{~m}$ of sediment is almost pure calcium carbonate. Total calcium carbonate decreases with depth until the base of Unit I is reached (Fig. 2) (Austin, Schlager, et al., 1986). In carbonate environments, aragonite generally undergoes a gradual change to calcite with increasing time, pressure, and burial depth (Bathurst, 1976). The mineralogy of Site 630 demonstrates this phenomenon, as aragonite decreases with depth, and by 70 mbsf it completely disappears (Austin, Schlager, et al., 1986). This decrease in aragonite is reflected in the specific gravity measured in the three samples (Table 2). Pure aragonite has a specific gravity between 2.85 and 2.94; calcite has a specific gravity of 2.711 (Hodgman et al., 1963).

\section{CONSOLIDATION CHARACTERISTICS}

Changes in the coefficient of consolidation, bulk modulus and its inverse, compressibility, and permeability can be related directly to the magnitude of overburden pressure by means of consolidation testing. When a sample is first placed under load, pore water carries the load. As the pore water drains from the sample, the load is transferred to the sediment structure, causing the realignment of grains and a more compact structure (Richards and Hamilton, 1967; Lambe and Whitman, 1979). 


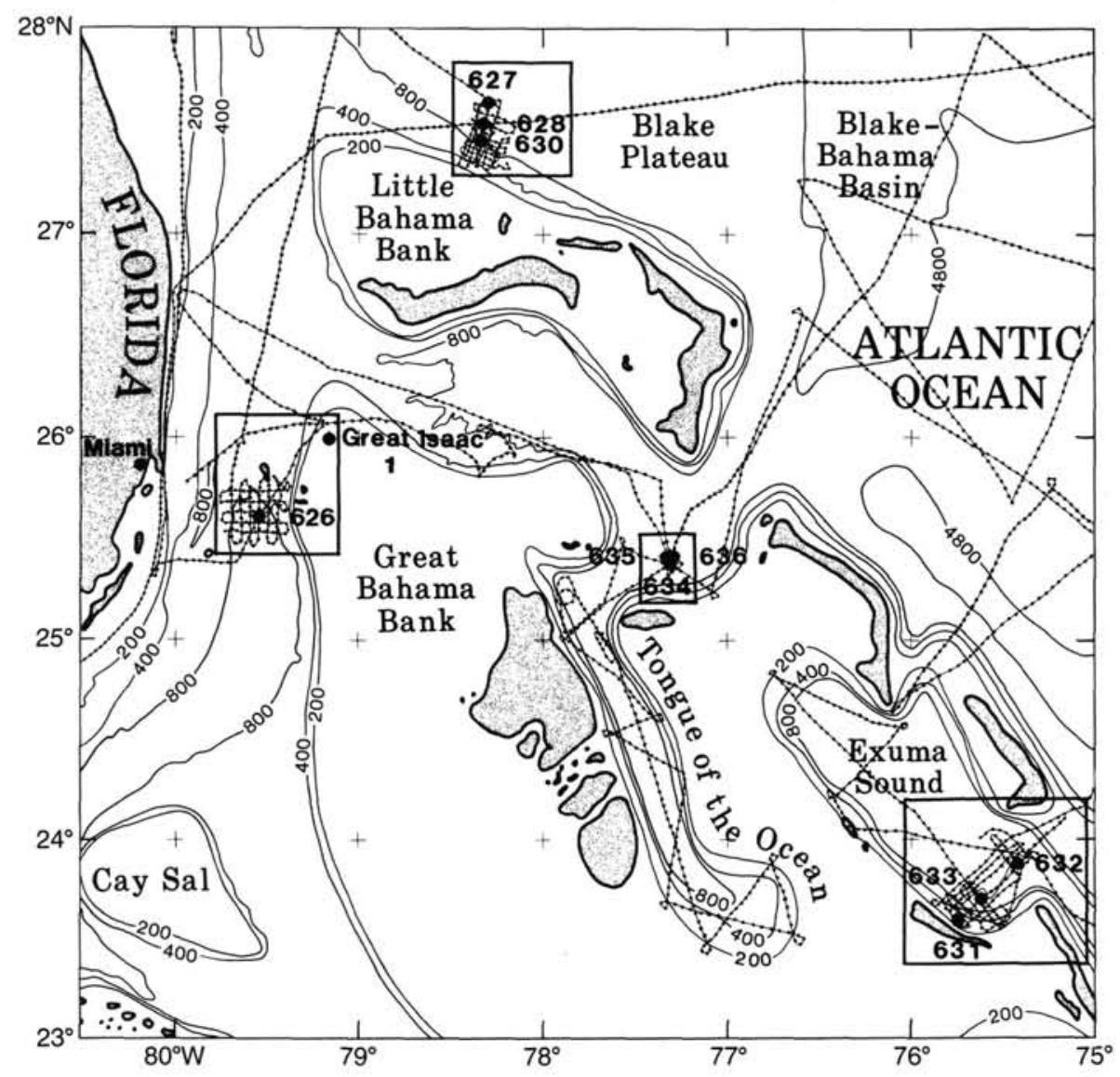

Figure 1. Location map of Leg 101 drilling sites. Site 630 is the shallowest site in a three-hole transect north of Little Bahama Bank. (From Austin, et al., this volume.)

Table 1. Comparison of Hole $630 \mathrm{~B}$ sample locations with Hole $630 \mathrm{~A}$ lithostratigraphy."

\begin{tabular}{|c|c|c|c|c|}
\hline Subunit & $\begin{array}{l}\text { Depth } \\
\text { (mbsf) }\end{array}$ & Age & Constituents & Section \\
\hline IA & $0-28$ & $\begin{array}{l}\text { early/late Pleisto- } \\
\text { cene }\end{array}$ & $\begin{array}{l}7.5 \% \text { foraminifers; } \\
15 \% \text { nannofossils; } 45 \% \text { micrite } \\
\quad \text { (grains smaller than } 25 \mu \text { ); } \\
\text { abundant aragonite }\end{array}$ & $\begin{array}{l}101-630 \mathrm{~B}-2 \mathrm{H}-5 \\
\quad(10.94-11.30 \mathrm{mbsf})\end{array}$ \\
\hline IB & $28-90$ & early Pliocene & $\begin{array}{l}10 \% \text { foraminifers; } 50 \% \\
\text { nannofossils; } 25 \% \text { micrite; } \\
\text { common aragonite }\end{array}$ & $\begin{array}{l}101-630 \mathrm{~B}-5 \mathrm{H}-6 \\
\quad(41.00-41.5 \mathrm{mbsf})\end{array}$ \\
\hline IC & $90-146$ & $\begin{array}{l}\text { late Miocene } \\
\text { early Pliocene }\end{array}$ & $\begin{array}{l}30 \% \text { foraminifers; } 40 \% \\
\text { nannofossils; } 15 \% \text { micrite; } \\
\text { rare aragonite }\end{array}$ & $\begin{array}{l}101-630 \mathrm{~B}-9 \mathrm{H}-6 \\
\quad(79.4-79.8 \mathrm{mbsf})\end{array}$ \\
\hline
\end{tabular}

a Depths shown correlate with depths within Subunits IA and IB from Hole 630A. Section 101-630B$9 \mathrm{H}-6$, although recovered from 79.4 to $79.8 \mathrm{mbsf}$, contains rare aragonite and is similar in composition to sediment recovered from Subunit IC.

The relationship between the amount of solid and void space is expressed by the void ratio $(e)$. Since the diameter of the sample is fixed during testing, the void ratio $(e)$ can be calculated from the change in sample height during the consolidation test. Plots of void ratio versus normal stress, e-log $p$ curves (Fig. 3), illustrate the results of consolidation tests from Hole 630B. Gentle curves without distinct inflection points are typical of either calcareous or disturbed samples.

Many marine sediments uppermost in the sediment column display an apparent overconsolidation often attributed to chemical alterations such as cementation (Bjerrum, 1967) or sediment cohesiveness. Otherwise, overconsolidation indicates that a sediment has had a greater overburden pressure at some time in the past. Erosion, slumping, and other combinations of geologic processes acting on the sediment may then remove overburden and decrease the overburden stress. In contrast, underconsolidation occurs when the present overburden creates a vertical effective stress greater than the effective stress calculated from consolidation tests. In general, underconsolidated sediments exhibit pore-water pressures greater than hydrostatic. Plotting the change in sample height divided by the sample height $(\Delta H / H)$ versus normal stress $\left(\sigma_{n}\right)$ (Fig. 4$)$ has the effect of normalizing the consolidation curves for different samples so that relative consolidation states can be inferred. 
Table 2. Index properties of sediments from Hole 630B. ${ }^{\mathrm{a}}$

\begin{tabular}{ccccccc}
\hline Section & $\begin{array}{c}\text { Aragonite } \\
(\%)\end{array}$ & $\begin{array}{c}\text { Specific } \\
\text { gravity } \\
\left(G_{s}\right)\end{array}$ & $\begin{array}{c}\text { Sand } \\
(\%)\end{array}$ & $\begin{array}{c}\text { Water } \\
\text { content } \\
(\%)\end{array}$ & $\begin{array}{c}\text { Porosity } \\
(\%)\end{array}$ & $\begin{array}{c}\text { Burial } \\
\text { depth } \\
(\mathrm{mbs})\end{array}$ \\
\hline $101-630 \mathrm{~B}-2 \mathrm{H}-5$ & $40-50$ & 2.77 & 63.5 & 46.14 & 54.01 & 10.9 \\
$101-630 \mathrm{~B}-5 \mathrm{H}-6$ & $20-30$ & 2.73 & 93.4 & 67.23 & 65.88 & 41.0 \\
$101-630 \mathrm{~B}-9 \mathrm{H}-5$ & Rare & 2.71 & 87.3 & 53.81 & 59.06 & 79.4 \\
\hline
\end{tabular}

a These shore-based measurements were made at Texas A\&M University.

Permeability changes with increasing consolidation are typically also plotted against void ratio (e) (Fig. 5). Calculated permeability values from consolidation characteristics generally show more scatter than do measured permeability values (Clukey and Silva, 1981), and measured values are probably closer to in-situ values of permeability than are the calculated values. Therefore, whenever possible, permeability is measured during the course of consolidation.

\section{SHEAR STRENGTH}

Shear strength defines the maximum shear stress that a sediment can withstand without failure under a given set of conditions. Shear strength can be defined by the following formula:

$$
S=C^{\prime}+\sigma_{n^{\prime}} \tan \phi^{\prime},
$$

where $C^{\prime}$ is the cohesion of the sediment, $\sigma_{n^{\prime}}$ is the effective normal stress (overburden pressure), and $\phi^{\prime}$ is the angle of internal friction. When sediments are stressed without loss of pore water (undrained condition), they respond as if they are cohesive material. In this case, the angle of internal friction $\left(\phi^{\prime}\right)$ equals 0 and the shear strength equals the cohesion $\left(S=C^{\prime}\right)$. Shear strength of the sediment as a function of overburden pressure can be determined by a series of triaxial and direct shear laboratory tests.

\section{METHODS}

\section{Hole 630A}

Physical-property measurements were made on hydraulic piston core/ extended core barrel (HPC/XCB) samples from Hole 630A at 3-m intervals on board ship using the pentapycnometer (Fig. 6) (Austin, Schlager, et al., 1986). Measurements of shear strength were made at the same sample interval with a miniature vane shear device (Fig. 7), a technique particularly well suited for testing cohesive sediments in an undrained condition. Tests were made by inserting the vane shear blade parallel to bedding after the core was split lengthwise (Austin, Schlager, et al., 1986).

Shore-based shear-wave velocity measurements were made whenever possible on the same discrete samples from which compressional-wave velocity measurements were made on board ship (Fig. 7). For this follow-up work, transducers (designed and fabricated at NORDA) utilizing piezoelectric bender elements were used to generate and receive shear waves at optimal frequencies of 1500 and $2000 \mathrm{~Hz}$ (Matthews, 1982).

\section{Hole $630 B$}

Whole-round samples were taken at three intervals from Hole 630B for shore-based geotechnical analyses: Samples 101-630B-2H-5, 114$150 \mathrm{~cm}$ (10.9-11.3 mbsf); 101-630B-5H-6, 110-150 cm (41.0-41.5 mbsf); and 101-630B-9H-6, $110-150 \mathrm{~cm}(79.4-79.8 \mathrm{mbsf})$. The top $5 \mathrm{~cm}$ of each sample was reserved for the laboratory consolidation tests, the middle $30 \mathrm{~cm}$ was used for triaxial shear-strength testing and direct shear testing, and the remainder was used to determine the grain size of each interval. Trimmings were used to determine moisture content, specific gravity, and initial void ratio prior to all consolidation and triaxial shear testing.

Shore-based analyses included the following:

1. Grain-size analyses: Grain sizes were determined for the three whole-round samples by separating the sand-sized fraction by wet sieving and the silt and clay size fraction by pipette analysis. See Folk (1974) for a complete discussion of this technique.

2. Consolidation testing: Samples were tested for degree of saturation using a Beckman pycnometer immediately before consolidation testing. Since all were within $\pm 2 \%$ of $100 \%$ saturation and did not require a back-pressure system to achieve saturation, a Soil Test consolidation frame with a fixed ring consolidimeter, $6.35 \mathrm{~cm}$ in diameter and $2.54 \mathrm{~cm}$ in height, was used. Loads were added incrementally in 24-hr periods. The initial vertical pressure was $0.5 \mathrm{~kg} / \mathrm{cm}^{2}(4.9 \mathrm{kPa})$. Each subsequent load was doubled until a total vertical pressure of $64 \mathrm{~kg} / \mathrm{cm}^{2}$ $(627.9 \mathrm{kPa})$ was reached. The sample was then unloaded at a ratio of $1 / 4$. Reloading took place until a total vertical pressure of $128 \mathrm{~kg} / \mathrm{cm}^{2}$ $(1255.7 \mathrm{kPa})$ was reached:

(a.) A consolidation curve of change in sample height versus the log of time was plotted for each load increment and the coefficient of consolidation $\left(C_{v 50}\right)$ was determined:

$$
C_{v 50}=T_{v 50}\left(H^{2}\right) / t_{50},
$$

where $T_{v 50}=0.197, H$ is half the sample height since the sample is allowed to drain from both top and bottom, and $t_{50}$ is the time on the midpoint of the consolidation curve between $t_{0}$ (extrapolated) and $t_{100}$ (Lambe, 1969).

(b.) Void ratio (e) was calculated for each load increment and plotted against the $\log$ of effective normal stress (the e-log $p$ curve, Fig. 3):

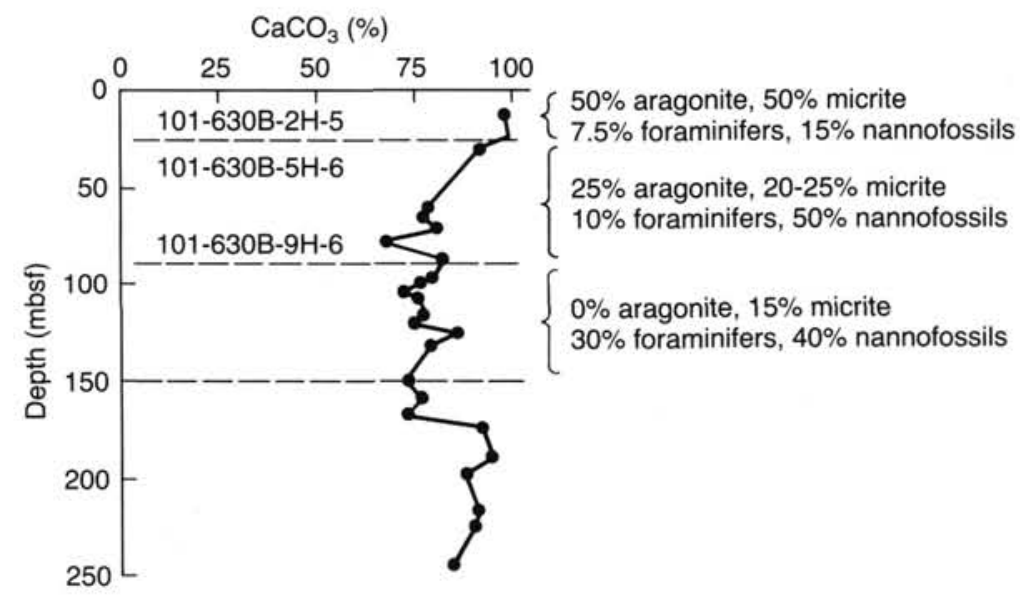

Figure 2. Percentage of total calcium carbonate plotted against depth (in mbsf) at Hole 630A. Shipboard calcium carbonate content determinations were made using the carbonate bomb method (Müller and Gastner, 1971). 


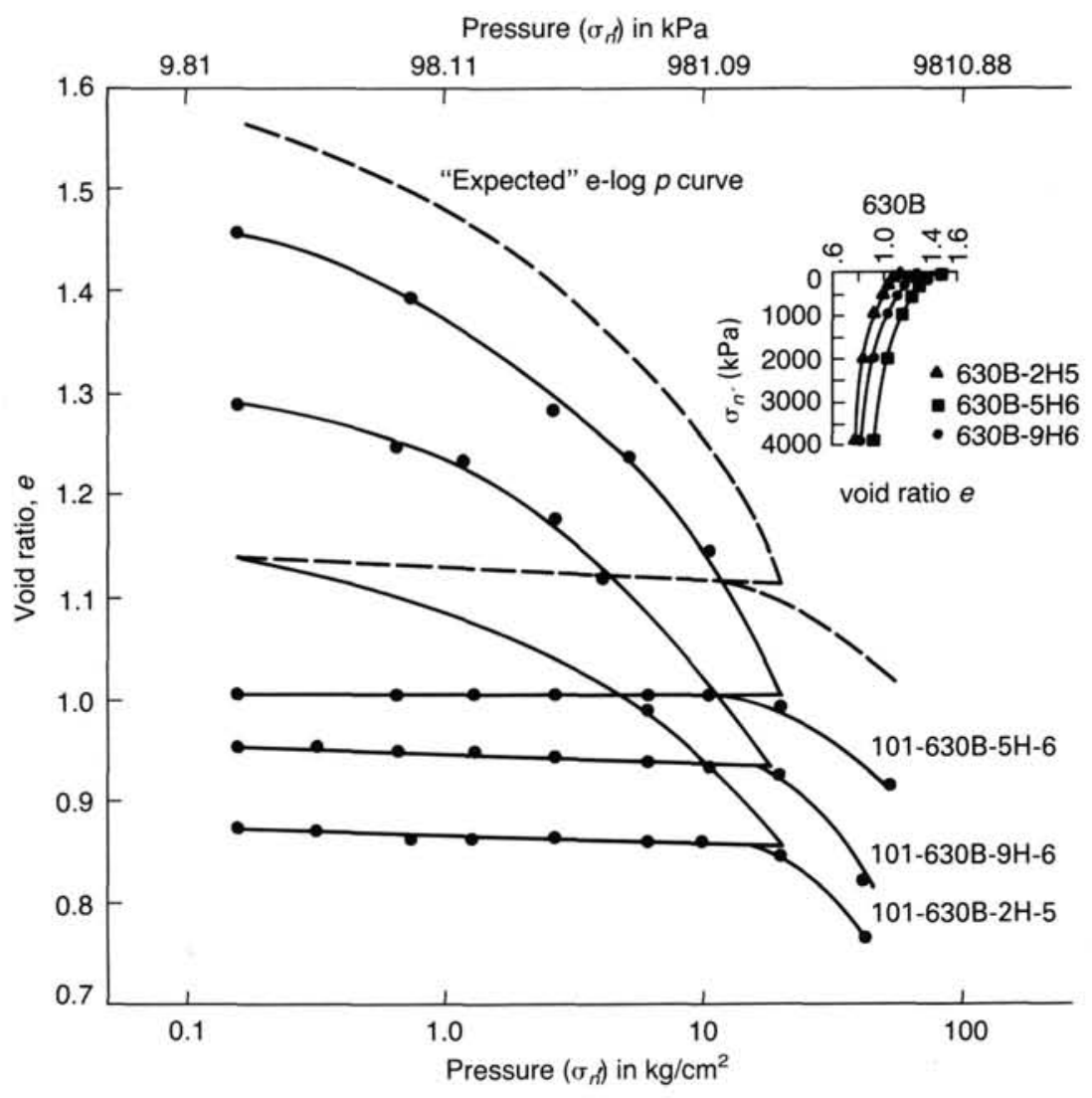

Figure 3. Two e-log $p$ curves: Void ratio $(e)$ plotted against applied normal stress $\left(\sigma_{n^{\prime}}\right)$ during consolidation illustrates (a) a general decrease in void ratio for increasing loads for all three sections and (b) lower than expected initial void ratio for Section 101-630B-2H-5 relative to Sections 101-630B-5H-6 and 101-630B-9H-6. Dashed curve indicates the expected e$\log p$ curve from Section 101-630B-2H-5.

$$
e=\left(h / W_{s} / \gamma_{s} \cdot A_{s}\right)-1,
$$

where $h$ is the height of the sample, $W_{s}$ is the dry weight of sediment, $\gamma_{s}$ is the unit weight of the sediment, and $A_{s}$ is the area of the sample.

(c.) The instantaneous slope of the e-log $p$ curve at any point $\left(A_{v}\right)$ is the coefficient of one-dimensional compressibility. Its inverse is the bulk modulus $(\mathrm{K})$ of the sample.

(d.) From $A_{v}$, the coefficient of one-dimensional compressibility $\left(M_{v}\right)$ is calculated:

$$
M_{v}=A_{v}\left(1 / 1+e_{0}\right) .
$$

(e.) Permeability $(k)$, the rate of flow past a specified area, is calculated from:

$$
k=C_{v 50} \cdot \gamma_{w} \cdot M_{v 50},
$$

where $C_{v 50}$ is the coefficient of consolidation, $\gamma_{w}$ is the unit weight of water, and $M_{v 50}$ is the coefficient of compressibility.

Permeability also was measured using a variable head permeameter (see Lambe, 1969) for each load increment beginning with a total vertical pressure of $2 \mathrm{~kg} / \mathrm{cm}^{2}(19.6 \mathrm{kPa})$. These results, corrected to $20^{\circ} \mathrm{C}$, were then compared to calculated values of permeability. In a saturated soil, water flow is laminar, and Darcy's Law applies:

$$
k=\frac{a L}{A\left(t_{1}-t_{0}\right)} \ln 10\left(h_{0}-h_{1}\right),
$$

where $a$ is the cross-sectional area of the standpipe, $L$ is the length of sediment, $A$ is the cross-sectional area of the sample, $t_{0}$ is the time when water in the standpipe is at $h_{0}, t_{1}$ is the time when water in the standpipe is at $h_{1}$, and $h_{0}$ and $h_{1}$ are the heads between which the permeability is determined.

3. Direct shear testing: A series of three consolidated, drained, direct shear tests were run on Section 101-630B-9H-6 using a WykehamFarrance direct shear machine, because the upper limit of the triaxial system confining pressure was only $120 \mathrm{psi}$, which precluded two final tests deemed desirable at higher confining pressures. The purpose of the direct shear tests was to determine the cohesion $\left(C^{\prime}\right)$ of Section 101-630B9H-6 (Fig. 8). The angle $\phi^{\prime}$ for the triaxial test of Section 101-630B-9H-6 could be determined by constructing the Mohr rupture envelope between $C$, known to be 0 from the direct shear test, and the tangent of the constructed Mohr's circle (Fig. 9). Normal stresses applied during direct shearing $\left(\sigma_{n}\right)$ were $148.7 \mathrm{psi}(1025 \mathrm{kPa}), 220.6 \mathrm{psi}(1520 \mathrm{kPa})$, and 292.6 psi $(2016 \mathrm{kPa})$. Shearing took place over a 2-wk period, at a rate of $0.00064 \mathrm{~mm} / \mathrm{min}$. for each sample, to ensure complete drainage without pore-pressure buildup. Pore pressures could not be monitored during the shear test using this system.

4. Triaxial testing: Consolidated, drained triaxial tests were performed on the remaining portions of each whole-round sample. Samples were saturated by increasing confining pressures until $B$ (pore-pressure parameter) values of 1 were reached, indicating $100 \%$ saturation. The samples were consolidated to approximately the in-situ effective stress on the sample using back-pressure consolidation. A Wykeham-Farrance triaxial apparatus was used. Samples were consolidated until well into secondary consolidation, as indicated by a plot of change in sample volume versus time (usually $12-24 \mathrm{hr}$ with these samples). Pore pressures were monitored continuously with a Druck transducer. Samples were sheared over a $12-\mathrm{hr}$ period at a rate of $0.003048 \mathrm{~mm} / \mathrm{min}$. Changes in sample volume were measured during shear. Because the sample volume changed continuously during shearing, a correction had to be applied to the deviator stress $\left(\sigma_{1}-\sigma_{3}\right)$ to account for energy lost during this volume change. Readings were corrected as follows: 


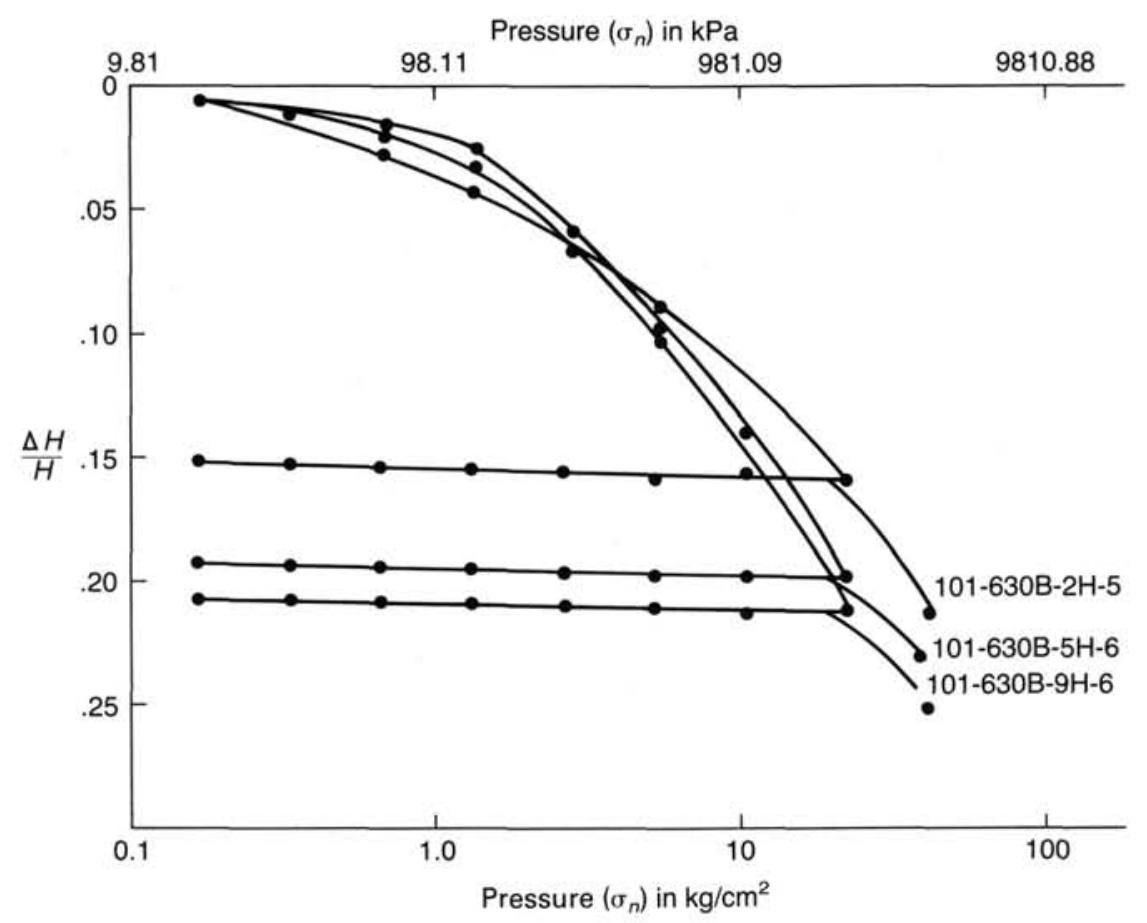

Figure 4. Curves of $\Delta H / H$ versus $\sigma_{n}$ illustrate that Section 101-630B-2H-5 is not overconsolidated relative to $101-630 \mathrm{~B}-5 \mathrm{H}-6$ and $101-630 \mathrm{~B}-9 \mathrm{H}-6$. The overall change in height is less than that for 101-630B-5H-6 and 101-630B-9H-6.

$$
\left(\sigma_{1}-\sigma_{3}\right)_{c}=\left(\sigma_{1}-\sigma_{3}\right)_{m}-f e \sigma_{3^{\prime}},
$$

where subscript $c$ indicates "corrected" and subscript $m$ indicates "measured" values, $f e$ is the slope of the curve of volume change plotted against strain, and $\sigma_{3}$ is the all-around, or confining, pressure under which the test was run (Skotheim et al., 1985). Samples from the three sections were run under the following near ambient consolidation pressures: Section 101-630B-2H-5: 15, 30, and 40 psi; Section 101-630B-5H-6: 60, 75, and $100 \mathrm{psi}$; and Section 101-630B-9H-6: 115 psi.

Results are in terms of effective stress since all tests were run drained. The straight line Mohr-Coulomb rupture envelope is a best-fit line, and $\phi^{\prime}$ is determined graphically (Fig. 9). The diameter of each Mohr's circle represents the deviator stress, $\sigma_{1}-\sigma_{3}$. The $y$-intercept $\left(C^{\prime}\right)$ is a measure of cohesion of the sample tested.

\section{RESULTS AND DISCUSSION}

Index-property values from Hole 630A plotted against depth (Fig. 6) illustrate that water content and porosity values are decreasing only slightly. Therefore, much of the overburden is still being carried by pore water. With water content remaining high, the sediment column is probably not undergoing significant consolidation.

Consolidation results are illustrated in Figure 3. The shapes of the e-log $p$ curves are typical of curves for calcareous sediments found by other workers (Demars, 1982; Lee, 1982; Valent et al., 1982). However, Section 101-630B-2H-5 has a lower void ratio than was expected given its shallow depth of burial. Initial void ratio $\left(e_{0}\right)$ for Section 101-630B-2H-5 is 1.16 , whereas for Section 101-630B-5H-6, it is 1.48, and for Section 101-630B-9H-6 it is 1.31. The expected e-log $p$ curve for Section 101-630B-2H-5 with an initial void ratio greater than 1.48 is illustrated by the dashed line (Fig. 3). Void ratio for each sample does decrease with increasing overburden pressure during consolidation as the grains become aligned and pore spaces close (Fig. 3).

Effective overburden stress $\left(\sigma_{0}\right.$, can be plotted vs. the actual depth of burial for a sample because, in the marine environment, sediments without excess pore pressures are consolidated under hydrostatic conditions (Taylor, 1948). This must be taken into account when calculating $\sigma_{0^{\prime}}$ :

$$
\left.\sigma_{0^{\prime}}=\left[\left(G_{s} \cdot \rho \text { freshwater }\right)-\rho \text { seawater }\right) Z /(1+e)\right],
$$

where $G_{s}$ is the specific gravity of the sediment grains, $e$ is the void ratio, $\rho$ is the density, and $Z$ is the depth below seafloor. The three Little Bahama Bank samples display some degree of consolidation with depth. However, it is evident (Fig. 10) that Section 101-630B-2H-5 (expected to have a more gentle gradient than that calculated) is behaving as if it should be deeper in the sediment column relative to the other two samples or, conversely, Sections 101-630B-5H-6 and 101-630B-9H-6 are behaving as though they should be shallower in the sediment column relative to Section 101-630B-2H-5. One would expect, therefore, that Section 101-630B-2H-5 would be more consolidated than Sections 101-630B-5H-5 or 101-630B-9H-6. However, when the change in sample height is plotted versus the effective normal stress (Fig. 4), comparison of the curves indicates that Section 101-630B-2H-5 is, in fact, not overconsolidated relative to Section 101-630B-5H-6 and 101-630B-9H-6. The long gentle slope of Section 101-630B-2H-5 is typical of carbonate sediments, whereas the greater inflection point evident in the other two is more typical of consolidation curves plotted for clay mineral samples (Demars, 1982; Lee, 1982; Valent et al., 1982). The consolidation results plotted may be dependent upon total carbonate content, since Sections 101-630B-5H-6 and 101-630B9H-6 have significantly less calcium carbonate than does 101630B-2H-5 (Fig. 2).

Coring disturbance, including sampling disturbance, which often produces gentle e- $\log p$ curves similar to calcium carbonate consolidation curves, is not a factor in these results because all three samples tested were treated identically. Visual inspection and sample preparation for consolidation testing did not result in any abnormal disturbance in any of the three samples tested. The apparent overconsolidation of Section 101-630B$2 \mathrm{H}-5$, therefore, cannot be attributed to coring disturbance. 


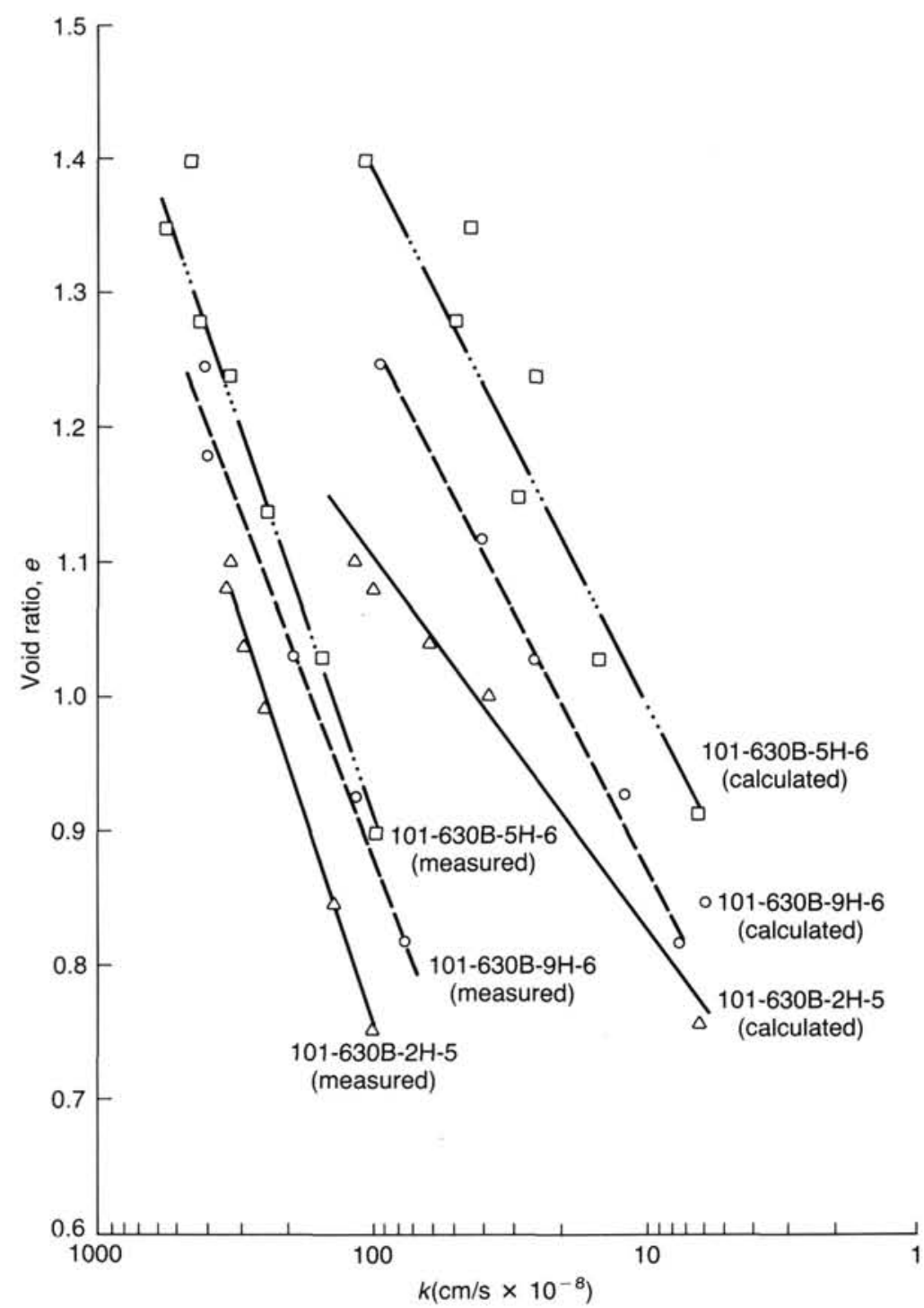

Figure 5. Plot of log of coefficient of permeability $(k)$ versus void ratio $(e)$. Measured values of $k$ show less variability and are probably closer to in-situ values of $k$ than the calculated values of $k$. Best-fit lines are drawn by visual inspection. Results are anomalous; it was expected that Section 101-630B-2H-5 would have a higher permeability than that measured.

The change in consolidation characteristics may be further influenced by the mineralogy of the calcareous constituents. As shown in Table 2, significant differences exist that might affect consolidation. Section 101-630B-2H-5 has a much lower sand content and a slightly lower water content and porosity than Section 101-630B-5H-6. The increasing percentage of sand in Sections 101-630B-5H-6 and 101-630B-9H-6 reflects the increasing number of sand-sized foraminifers in those samples (Austin, Schlager, et al., 1986). Foraminifer-rich sediments, in general, have high total porosity, in part because the interior of the foraminifer test is not solid but is gas or water filled, resulting in high intraparticle porosity (Flugel, 1978). Section 101-630B-2H-5 has fewer foraminifers, and the grains are primarily aragonite aggregates and smaller, unidentified fragments. Measured porosity is primarily interparticle porosity (i.e., the pore water is located between grains).

Consolidation results, including permeability values, are presented in Table 3. A plot of permeability versus void ratio is presented in Figure 5. Permeability values calculated from consolidation characteristics are higher and show more scatter than do measured permeability values. Section 101-630B-2H-5, with slightly lower porosity and water content, also has a lower calculated and measured permeability than do the two intervals recovered deeper in the section; this may be related to the constituents within the sections. Sections 101-630B-5H-6 and 101630B-9H-6, having a higher percentage of foraminifers and only slightly higher total porosity, have a higher permeability, perhaps because the high-porosity foraminifer grains became crushed during consolidation, resulting in a much more effective fluid loss. Connection of pore spaces after crushing of grains results in a higher permeability in the sample.

Section 101-630B-2H-5 may be characterized as having a larger fraction of its grains matrix-supported. Matrix material, when composed of aragonite crystals, may display high permeability because the needles are stacked randomly, allowing flowage of pore water (Fig. 11). The total amount of matrix material 
PROPERTIES OF SEDIMENTS IN A CARBONATE-SLOPE ENVIRONMENT

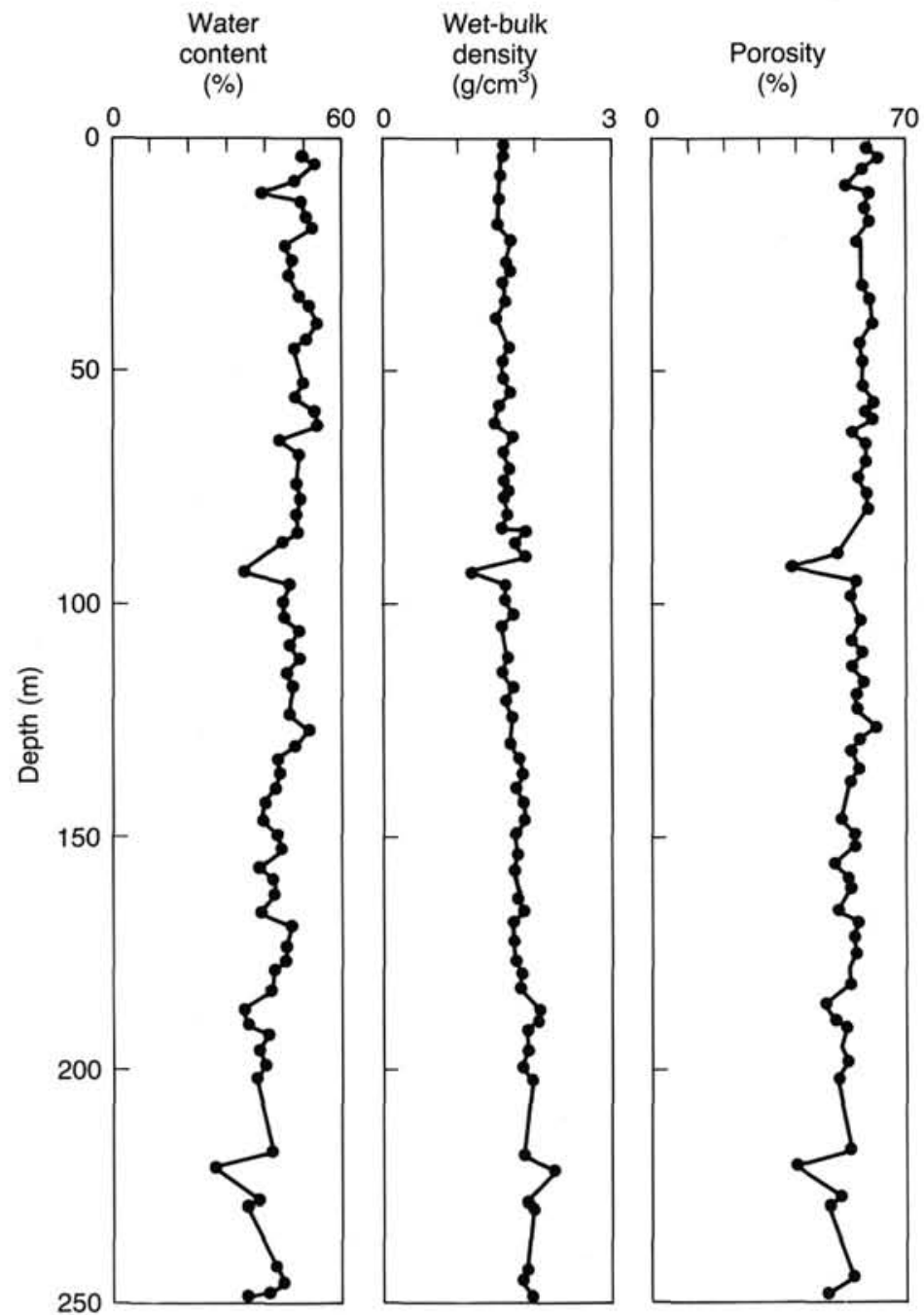

Figure 6. Shipboard index-property values from Hole 630A made with the pentapycnometer.
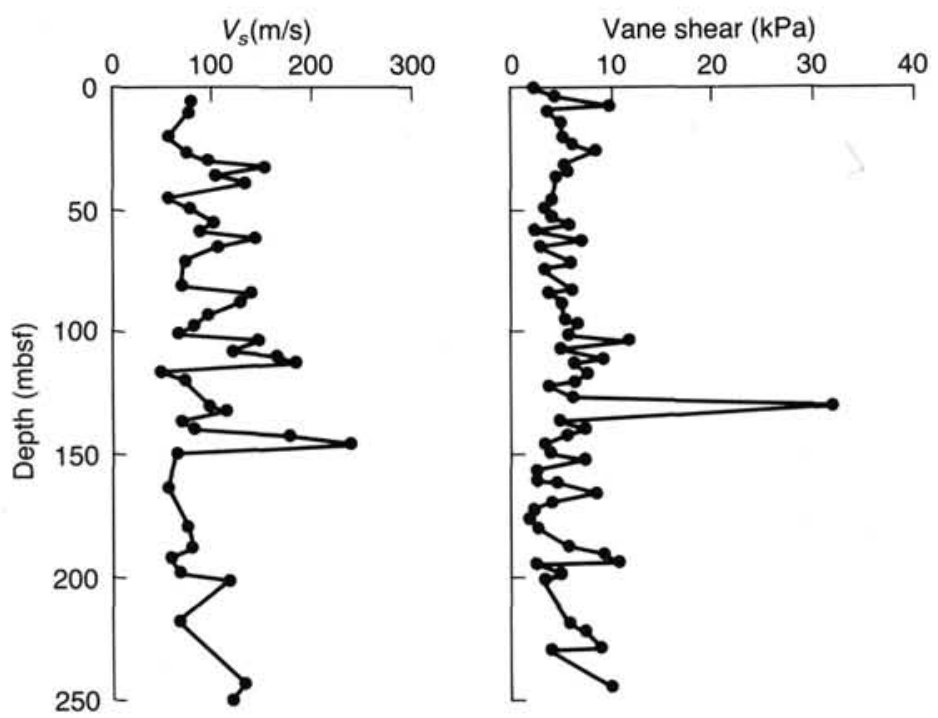

Figure 7. Plots illustrating the variability of undrained shear strength and shear-wave velocity with depth (mbsf) for Hole 630A. Although there is considerable variability between discrete samples, there is no overall increase in shear velocity and shear strength with depth. 


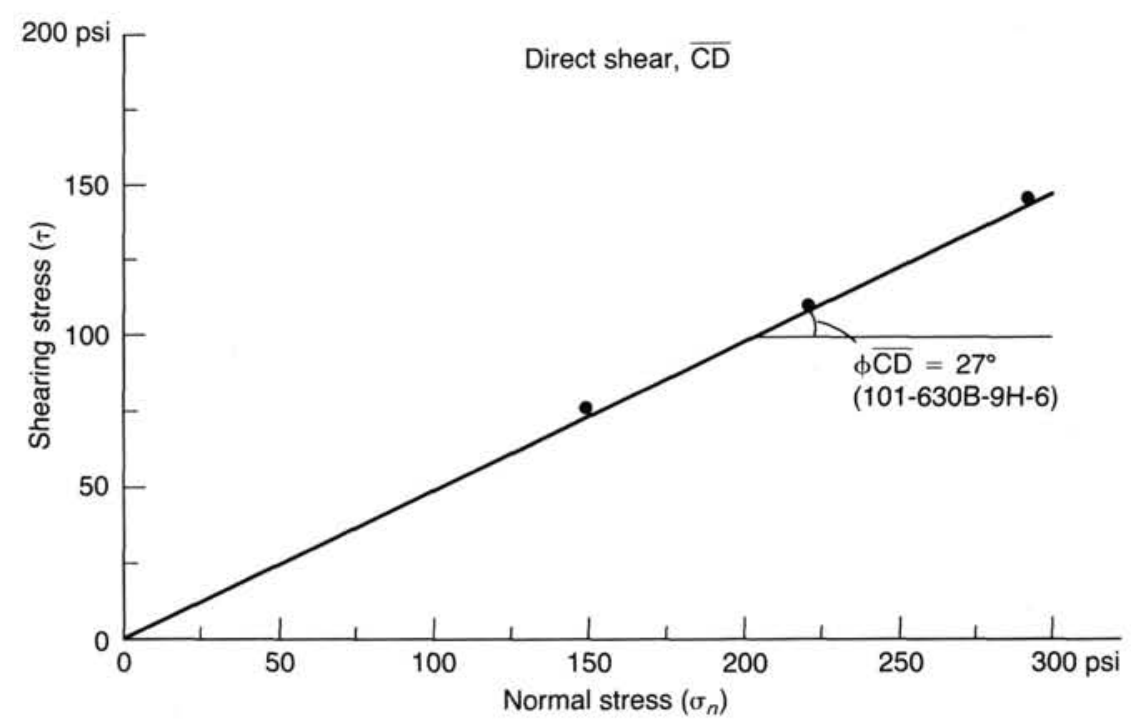

Figure 8. Direct shear-test results from Section 101-630B-9H-6. The strength envelope derived from test results has a $y$-intercept of zero, indicating that the section is cohesionless.

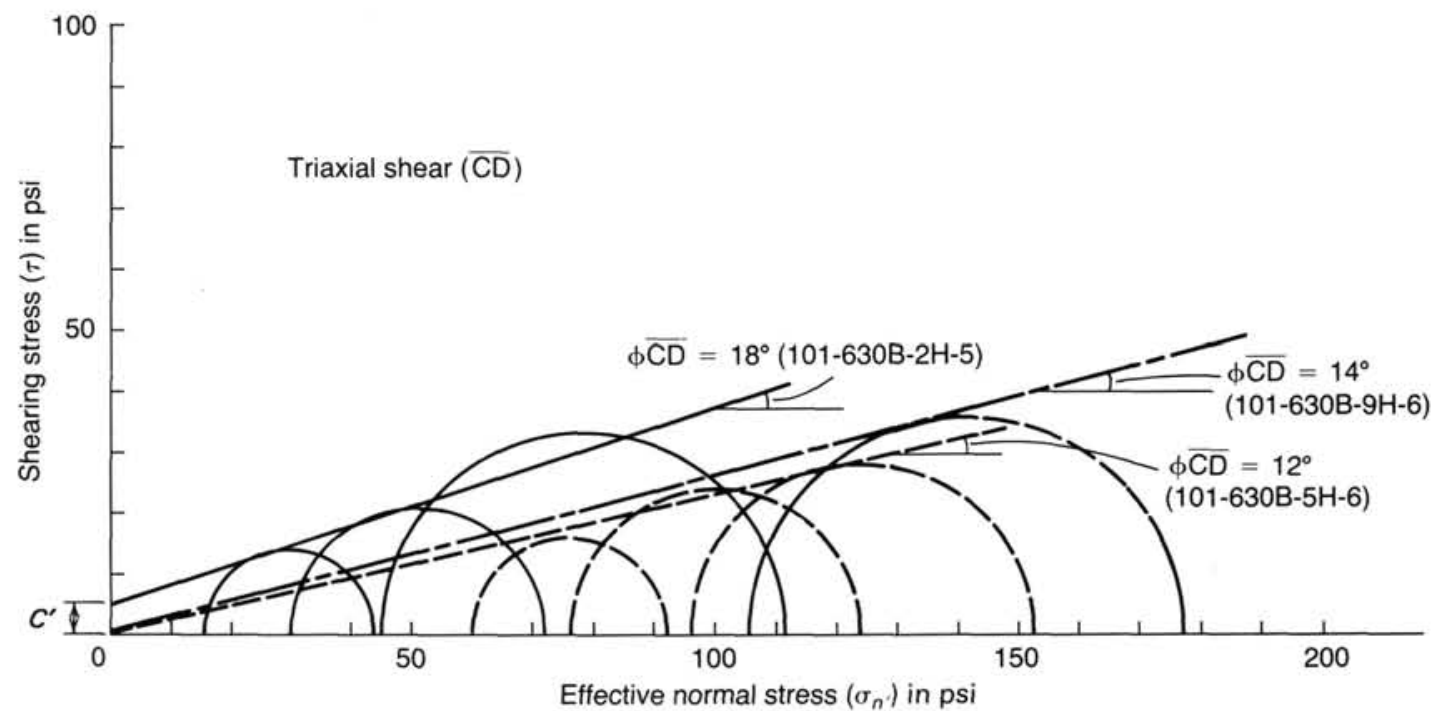

Figure 9. Graphic illustration of triaxial test results. Shear-strength envelopes for Sections 101-630B-2H-5 and 101630B-5H-6 were constructed through the tangents of the appropriate Mohr's circles. The shear-strength envelope for Section 101-630B-9H-6 was constructed from the origin through the tangent of the one possible Mohr's circle since direct shear testing indicated that the section was cohesionless. Angles $\phi \overline{\mathrm{CD}}$ are graphically determined.

vs. grains determines the measured permeability. As the percentage of aragonite (Table 1) and the total carbonate content (Fig. 2) decrease below 30 mbsf in Hole 630A, the matrix material must be composed of a higher proportion of noncarbonate components. Clay minerals tend to fill and block pore spaces, often resulting in a lower initial permeability. This initial permeability (Fig. 5) could not be measured in sediments below 30 mbsf in Hole 630B because the sample was cohesionless and material was lost until weights of greater than $1 \mathrm{~kg}$ were loaded.

Although increased grain alignment and increased strength resulting from the consolidation process probably occurred in all three samples, when the foraminifer tests were crushed during consolidation, pore spaces became interconnected, and permeability increased. Therefore, the differences in initial (i.e., pre-test) sample porosity, and the matrix to grain ratio, resulted in an initial difference in consolidation characteristics. None- theless, the small decrease in water content with depth (Fig. 6) indicates that little consolidation has occurred in the slope section as a whole near Site 630. However, other factors that might affect these consolidation results include cementation and environmental changes such as $\mathrm{pH}$, temperature, and salt concentration.

\section{SHEAR-STRENGTH RESULTS}

Data from triaxial shear tests and direct shear tests (tabulated in Table 4 and illustrated in Figs. 8 and 9) support the idea that little consolidation has occurred within the upper 79 mbsf at Site 630. Section 101-630B-2H-5 has a significantly higher shear strength than either Sections 101-630B-5H-6 or 101-630B$9 \mathrm{H}-6$, as indicated by the higher angle of internal friction $\left(18.5^{\circ}\right)$. Section 101-630B-2H-5 is the only sample with any measurable cohesion, about 5 psi. Sections 101-630B-5H-6 and 101-630B- 


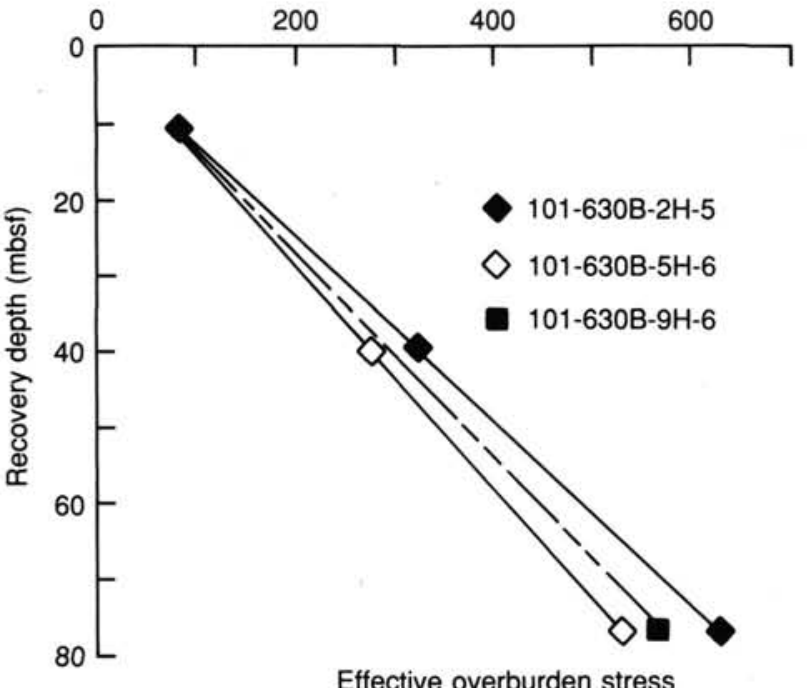

Effective overburden stress

$\left(\sigma_{n^{\prime}}\right)$ in $\mathrm{kPa}$

Figure 10. Effective overburden stress $\left(\sigma_{n^{\prime}}\right)$ plotted against depth of recovery. Results are extrapolated to shallower depths for Sections 101630B-5H-6 and 101-630B-9H-6.

9H-6 are cohesionless. Therefore, the shear strength of Sections 101-630B-5H-6 and 101-630B-9H-6 is a measure of the intergranular friction within these samples.

It was expected that shear strength results from triaxial testing on Hole $630 \mathrm{~B}$ samples could be compared qualitatively to the undrained, miniature vane shear strength results from Hole 630A (see Austin, Schlager, et al., 1986). If a correlation exists between triaxial and vane shear strength results, then fewer timeconsuming triaxial shear tests need to be performed on these types of sediments in the future. However, vane strength results plotted on board ship (Fig. 7) indicate a potential problem with vane shear testing of carbonate material. Measured values are low, less than $10 \mathrm{kPa}(1.45 \mathrm{psi})$, with very little increase in strength over the entire $250 \mathrm{~m}$ of sediment recovered at Site 630 . A ratio of undrained shear strength $\left(C_{u}\right)$ to overburden pressure $(P)$ of $\sim 0.23$ was derived from in-situ vane shear measurements on surficial carbonate sediments recovered from $1000 \mathrm{~m}$ (water depth) on the Blake Plateau (Valent et al., 1982). If this ratio is applied to sediments from Hole $630 \mathrm{~B}$, then the undrained shear strength at 100 mbsf in Hole 630B should be about $165 \mathrm{kPa}$, and at 250 mbsf about $409 \mathrm{kPa}$, well above the measured 10 $\mathrm{kPa}$.

The carbonate sediments sampled in Hole 630B appear to be cohesionless materials whose strength depends primarily on effective confining stress and hence on intergranular friction. When these cohesionless sediments are brought to the surface, this effective confining stress is removed. Consequently, shipboard measurements of undrained strength made on unconfined samples of such sediments are probably meaningless. Consolidated triaxial and direct shear measurements of strength give values of shear strength more representative of in-situ values. Vane shear measurements are not representative of in-situ undrained shear strength.

Shear-wave velocity measurements made on samples from Hole $630 \mathrm{~A}$ illustrate the same problem. It was expected that an increase in shear wave velocity could be correlated with an increase in shear strength. Shear-wave velocity values can be pre-

Table 3. Consolidation test results.

\begin{tabular}{|c|c|c|c|c|c|c|}
\hline $\begin{array}{l}\text { Pressure } \\
\left(\mathrm{kg} / \mathrm{cm}^{2}\right)\end{array}$ & $\begin{array}{c}C_{v 50} \\
\left(\mathrm{~cm}^{2} / \mathrm{s}\right)\end{array}$ & $\stackrel{A_{v}}{\left(\mathrm{~cm}^{2} / \mathrm{kg}\right)}$ & $\underset{\left(\mathrm{cm}^{2} / \mathrm{kg}\right)}{M_{v}}$ & $e$ & $\begin{array}{c}k \text { (calc) } \\
(\mathrm{cm} / \mathrm{s})\end{array}$ & $\begin{array}{c}k \text { (meas) } \\
(\mathrm{cm} / \mathrm{s})\end{array}$ \\
\hline \multicolumn{7}{|c|}{ Section 101-630B-2H-5 } \\
\hline $\begin{array}{l}0 \\
0.158 \\
0.316 \\
0.632 \\
1.26 \\
2.52 \\
5.05 \\
10.1 \\
20.2 \\
40.4\end{array}$ & $\begin{array}{l}3.50 \cdot 10^{-2} \\
3.76 \cdot 10^{-2} \\
4.08 \cdot 10^{-2} \\
5.01 \cdot 10^{-2} \\
4.11 \cdot 10^{-2} \\
3.74 \cdot 10^{-2} \\
1.75 \cdot 10^{-2} \\
1.47 \cdot 10^{-2} \\
2.86 \cdot 10^{-2}\end{array}$ & $\begin{array}{l}5.79 \cdot 10^{-2} \\
4.06 \cdot 10^{-2} \\
2.92 \cdot 10^{-2} \\
1.92 \cdot 10^{-2} \\
1.29 \cdot 10^{-2} \\
7.50 \cdot 10^{-3} \\
3.90 \cdot 10^{-3}\end{array}$ & $\begin{array}{l}2.73 \cdot 10^{-2} \\
1.93 \cdot 10^{-2} \\
1.39 \cdot 10^{-2} \\
9.40 \cdot 10^{-3} \\
6.50 \cdot 10^{-3} \\
3.90 \cdot 10^{-3} \\
2.10 \cdot 10^{-3}\end{array}$ & $\begin{array}{l}1.16 \\
1.14 \\
1.12 \\
1.10 \\
1.08 \\
1.04 \\
0.99 \\
0.93 \\
0.85 \\
0.76\end{array}$ & $\begin{array}{l}1.11 \cdot 10^{-6} \\
9.67 \cdot 10^{-7} \\
5.73 \cdot 10^{-7} \\
3.52 \cdot 10^{-7} \\
1.14 \cdot 10^{-7} \\
5.71 \cdot 10^{-8} \\
6.05 \cdot 10^{-8}\end{array}$ & $\begin{array}{l}3.17 \cdot 10^{-6} \\
3.17 \cdot 10^{-6} \\
2.88 \cdot 10^{-6} \\
2.34 \cdot 10^{-6} \\
1.74 \cdot 10^{-6} \\
1.31 \cdot 10^{-6} \\
9.09 \cdot 10^{-6}\end{array}$ \\
\hline \multicolumn{7}{|c|}{ Section 101-630B-5H-6 } \\
\hline $\begin{array}{l}0 \\
0.158 \\
0.316 \\
0.632 \\
1.26 \\
2.52 \\
5.05 \\
10.1 \\
20.2 \\
40.4\end{array}$ & $\begin{array}{l}2.91 \cdot 10^{-2} \\
3.67 \cdot 10^{-2} \\
2.50 \cdot 10^{-2} \\
1.32 \cdot 10^{-2} \\
2.30 \cdot 10^{-3} \\
3.43 \cdot 10^{-2} \\
3.08 \cdot 10^{-2} \\
2.68 \cdot 10^{-2} \\
2.70 \cdot 10^{-2}\end{array}$ & $\begin{array}{l}9.80 \cdot 10^{-2} \\
7.64 \cdot 10^{-2} \\
5.08 \cdot 10^{-2} \\
1.58 \cdot 10^{-2} \\
2.02 \cdot 10^{-2} \\
1.14 \cdot 10^{-2} \\
5.10 \cdot 10^{-3}\end{array}$ & $\begin{array}{l}4.04 \cdot 10^{-2} \\
3.19 \cdot 10^{-2} \\
2.16 \cdot 10^{-2} \\
6.90 \cdot 10^{-2} \\
9.00 \cdot 10^{-3} \\
5.30 \cdot 10^{-3} \\
2.50 \cdot 10^{-3}\end{array}$ & $\begin{array}{l}1.48 \\
1.45 \\
1.43 \\
1.40 \\
1.35 \\
1.28 \\
1.24 \\
1.14 \\
1.03 \\
0.92\end{array}$ & $\begin{array}{l}1.01 \cdot 10^{-7} \\
4.21 \cdot 10^{-7} \\
4.98 \cdot 10^{-7} \\
2.37 \cdot 10^{-7} \\
2.77 \cdot 10^{-7} \\
1.42 \cdot 10^{-7} \\
6.76 \cdot 10^{-8}\end{array}$ & $\begin{array}{l}4.50 \cdot 10^{-6} \\
5.54 \cdot 10^{-6} \\
4.14 \cdot 10^{-6} \\
3.22 \cdot 10^{-6} \\
2.38 \cdot 10^{-6} \\
1.55 \cdot 10^{-6} \\
9.68 \cdot 10^{-7}\end{array}$ \\
\hline \multicolumn{7}{|c|}{ Section 101-630B-9H-6 } \\
\hline $\begin{array}{l}0 \\
0.158 \\
0.316 \\
0.632 \\
1.26 \\
2.52 \\
5.05 \\
10.1 \\
20.2 \\
40.4\end{array}$ & $\begin{array}{l}3.76 \cdot 10^{-2} \\
3.70 \cdot 10^{-2} \\
3.38 \cdot 10^{-2} \\
2.84 \cdot 10^{-2} \\
2.80 \cdot 10^{-2} \\
3.65 \cdot 10^{-2} \\
2.93 \cdot 10^{-2} \\
2.22 \cdot 10^{-2} \\
2.80 \cdot 10^{-2}\end{array}$ & $\begin{array}{l}6.33 \cdot 10^{-2} \\
1.59 \cdot 10^{-2} \\
4.76 \cdot 10^{-2} \\
2.37 \cdot 10^{-2} \\
1.81 \cdot 10^{-2} \\
9.80 \cdot 10^{-2} \\
5.00 \cdot 10^{-3}\end{array}$ & $\begin{array}{l}2.79 \cdot 10^{-2} \\
7.10 \cdot 10^{-3} \\
2.13 \cdot 10^{-2} \\
1.09 \cdot 10^{-2} \\
8.60 \cdot 10^{-3} \\
4.80 \cdot 10^{-3} \\
2.60 \cdot 10^{-3}\end{array}$ & $\begin{array}{l}1.31 \\
1.29 \\
1.27 \\
1.25 \\
1.24 \\
1.18 \\
1.12 \\
1.03 \\
0.93 \\
0.82\end{array}$ & $\begin{array}{l}9.42 \cdot 10^{-7} \\
2.01 \cdot 10^{-7} \\
5.95 \cdot 10^{-7} \\
3.97 \cdot 10^{-7} \\
2.51 \cdot 10^{-7} \\
1.06 \cdot 10^{-7} \\
7.22 \cdot 10^{-8}\end{array}$ & $\begin{array}{l}3.49 \cdot 10^{-6} \\
3.42 \cdot 10^{-6} \\
2.99 \cdot 10^{-6} \\
3.15 \cdot 10^{-6} \\
1.86 \cdot 10^{-6} \\
1.12 \cdot 10^{-6} \\
7.52 \cdot 10^{-7}\end{array}$ \\
\hline
\end{tabular}




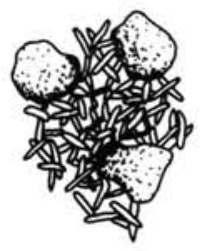

(a) Matrix-supported aragonite Interparticle porosity: high Intraparticle porosity: low Total porosity: medium Permeability: medium

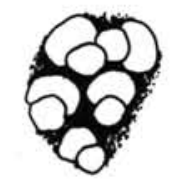

(b) Matrix-supported (clay and smaller particles) Interparticle porosity: low-medium Intraparticle porosity: high Total porosity: medium-high Permeability: low-medium

Figure 11. Sediment models of grains supported (a) in an aragonite matrix vs. grains supported (b) in a clayey matrix.

Table 4. Triaxial and direct shear results.

\begin{tabular}{ccccc}
\hline & & Psi \\
$\begin{array}{c}\sigma_{n} \\
(\mathrm{psi})\end{array}$ & $\begin{array}{c}\sigma_{1}-\sigma_{3} \\
(\mathrm{psi})\end{array}$ & $\phi$ & $C(\mathrm{psi})$ & $\begin{array}{c}\left(a t \sigma_{n} \text { of }\right. \\
30 \mathrm{psi})\end{array}$ \\
\multicolumn{3}{c}{ Triaxial test: }
\end{tabular}

Section 101-630B-2H-5

\begin{tabular}{|c|c|c|c|c|}
\hline $\begin{array}{l}15 \\
30 \\
45\end{array}$ & $\begin{array}{l}27.65 \\
42.50 \\
66.08\end{array}$ & $18.5^{\circ}$ & 5 & 15.04 \\
\hline \multicolumn{5}{|c|}{ Section 101-630B-5H-6 } \\
\hline 60 & 33.19 & $12^{\circ}$ & & 6.38 \\
\hline 75 & 48.99 & & $0-1$ & \\
\hline 100 & 56.68 & & & \\
\hline \multicolumn{5}{|c|}{ Section 101-630B-9H-6 } \\
\hline 115 & 70.84 & $14^{\circ}$ & 0 & 6.10 \\
\hline \multicolumn{5}{|c|}{ Direct shear: } \\
\hline \multicolumn{5}{|c|}{ Section 101-630B-9H-6 } \\
\hline 148.7 & 81.7 & $27^{\circ}$ & 0 & 13.9 \\
\hline 220 & 113.9 & & & \\
\hline 292.6 & 150.2 & & & \\
\hline
\end{tabular}

dicted from regression equations for carbonate sediments developed by Hamilton (1980) and from measured compressionalwave velocities:

$$
V_{s}=0.991-1.136\left(V_{p}\right)+0.47\left(V_{p}^{2}\right),
$$

where $V_{s}$ is shear wave velocity and $V_{p}$ is compressional-wave velocity in $\mathrm{km} / \mathrm{s}$. This equation was developed using measured data from the Ontong Java Plateau, where the sediment is a foraminiferal ooze. Using this equation, shear-wave values at 10.3 , 40,78 , and $249.4 \mathrm{mbsf}$ should be $416,412,443$, and $577 \mathrm{~m} / \mathrm{s}$, respectively. It is apparent that measured shear velocity is low initially and does not increase as predicted with depth (Fig. 7). As with shear strength, shear wave velocity of a cohesionless sediment depends on the effective confining pressure and cannot be measured accurately in the absence of confining pressure (i.e., on board ship).

An expected compressional-wave velocity increase with depth in calcareous foraminiferal ooze sediments was also predicted by Hamilton (1980):

$$
V_{p}(z)=V_{p 0}+1.713(z)-0.374\left(z^{2}\right),
$$

where $V_{p 0}$ is initial compressional velocity in $\mathrm{km} / \mathrm{s}$ and $z$ is depth in $\mathrm{km}$. With a measured initial compressional velocity of $1696 \mathrm{~m} / \mathrm{s}$ (Austin, Schlager, et al., 1986), compressional velocity at 40,78 , and $249.4 \mathrm{mbsf}$ should be 1764,1827 , and $2100 \mathrm{~m} / \mathrm{s}$, respectively. These calculated values are higher than the measured 1707, 1757, and $1970 \mathrm{~m} / \mathrm{s}$ values. Apparently, compressional-wave velocity does increase as a function of depth or overburden pressure, but not as predicted. Like undrained shear strength, velocity is dependent upon the rigidity of the material. Without an increase in rigidity and strength, an increase in velocity will not occur. Therefore, shear-wave velocity measurements made on unconfined periplatform oozes are probably not representative of in-situ values. However, compressional-wave velocity measurements may be closer to in-situ values because they are less dependent on shear rigidity (modulus) than are shear-wave velocity measurements.

To make these results relevant in a slope environment, the stability of these sediments was calculated based on the measured consolidated and drained shear strength, more representative of in-situ values. For submarine deposits and where the slope gradients and slumping mechanics are known only generally, the infinite slope stability analysis technique is appropriate (Morgenstern, 1969). A constant slope of unlimited extent is assumed. The forces acting on a saturated sedimentary slope with an inclination, $i$, and a sediment column of $z$ thickness on a plane $A-B$ are illustrated in Figure 12 (redrawn from Keller et al., 1979). The weight of a sediment column of width $b \cos i$ is:

$$
\left[\left(G_{s} \cdot \rho \text { freshwater }\right)-\rho \text { seawater }\right] /(1+e) \cdot Z \cdot b \cos i,
$$

where $\left(G_{s} \cdot \rho\right.$ freshwater $)$ - $\rho$ seawater is the buoyant density of the sediment, $z$ is the depth of sediment to the layer in question, and $b$ is the unit area. The forces acting on the sediment can be resolved into a shear stress, $\tau$, and a vertical stress, $P_{v} . \tau$ can be calculated:

$$
\begin{aligned}
\tau & =P_{\mathrm{v}} \sin i \\
P_{v} & =\left(G_{s} \cdot \rho \text { freshwater }\right)-\rho \text { seawater } /(1+e) Z \cos i ;
\end{aligned}
$$

therefore:

$$
\tau=\left(G_{s} \cdot \rho \text { freshwater }\right)-\rho \text { seawater } /(1+e) Z \sin i \cos i .
$$

When $\tau$ is plotted against $\sigma_{n}$ as in Figure 12(c), a strength envelope $A-B-D$ can be drawn. Any vertical stress $(\tau)$ less than $B-E$ results in a shear stress lower than the shear strength of the sediment, and hence the sediment is stable on that slope. As the overburden pressure increases such that the shear strength of the sediment is exceeded and $\tau$ becomes larger than $B-E$, the slope becomes unstable.

Assuming that the sediment is homogeneous to the level of Section 101-630B-2H-5, the calculation of $\tau$ from a laboratoryderived angle of internal friction (Fig. 9) suggests that a slope inclination greater than $18^{\circ}$ is unstable. Figure 13 shows the slope of inclination plotted against the ratio between the measured consolidated and drained shear strength, and the shear strength needed to prevent slope failure (safety factor). A safety factor of 1 indicates that the strength of the sediment is exactly that needed to prevent slope failure and that such failure is imminent. Sections 101-630B-9H-6 and 101-630B-5H-6 plot as one line because the calculations of safety factor vs. inclination are very close and both will fail at just under $14^{\circ}$. These strength values are considerably lower than those generally measured from uniform foraminiferal oozes $\left(28^{\circ}-32^{\circ}\right.$, Valent et al., 1982). The implication is that a very small triggering mechanism could start 

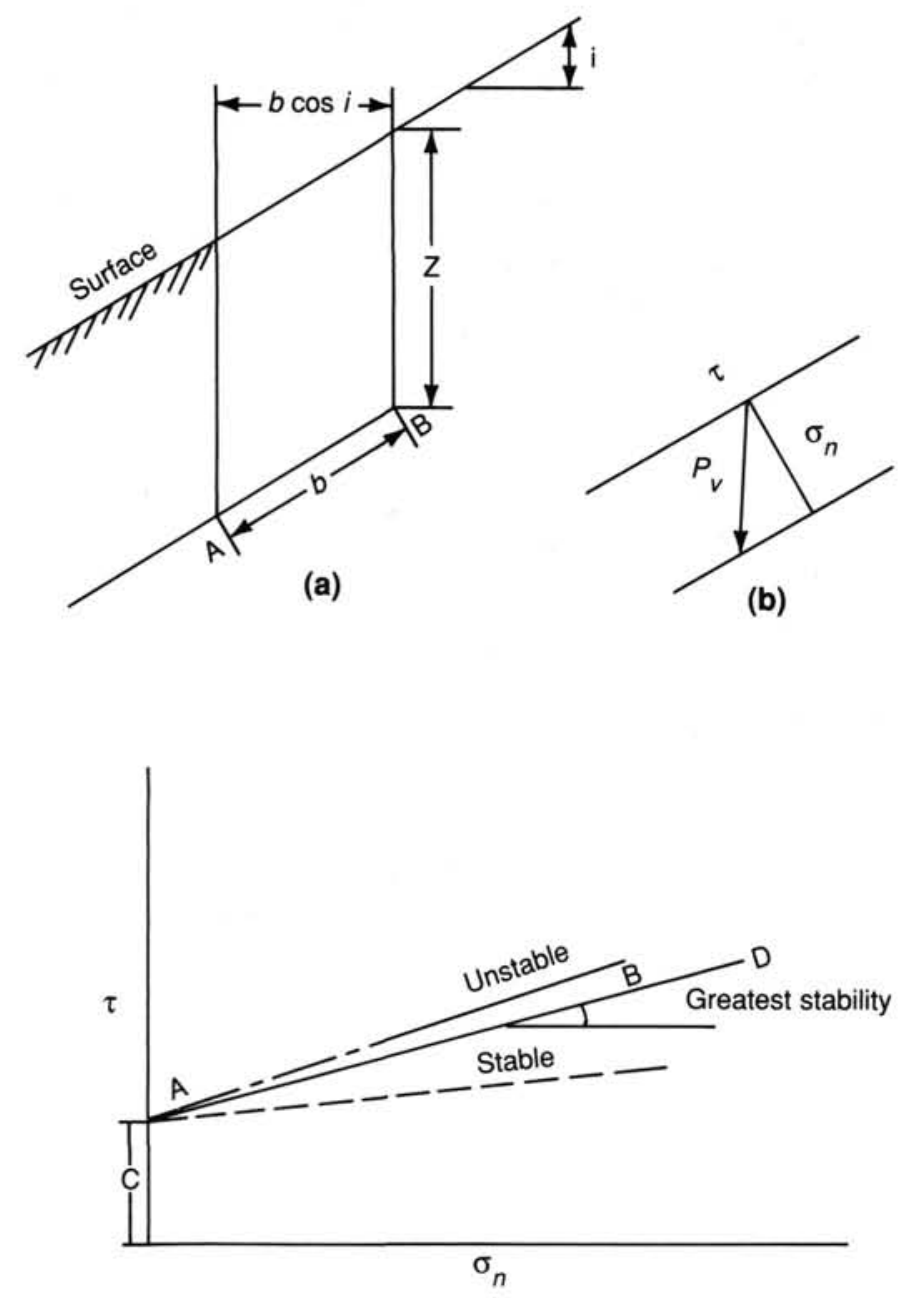

(c)

Figure $12(\mathrm{a}, \mathrm{b})$. Illustration of the vertical pressures on a sedimentary slope redrawn from Keller et al. (1979). (c). Strength envelope $A-B-D$ exhibits the greatest angle possible before slope failure occurs. A slope with a $\tau$ greater than $B-E$ is unstable.

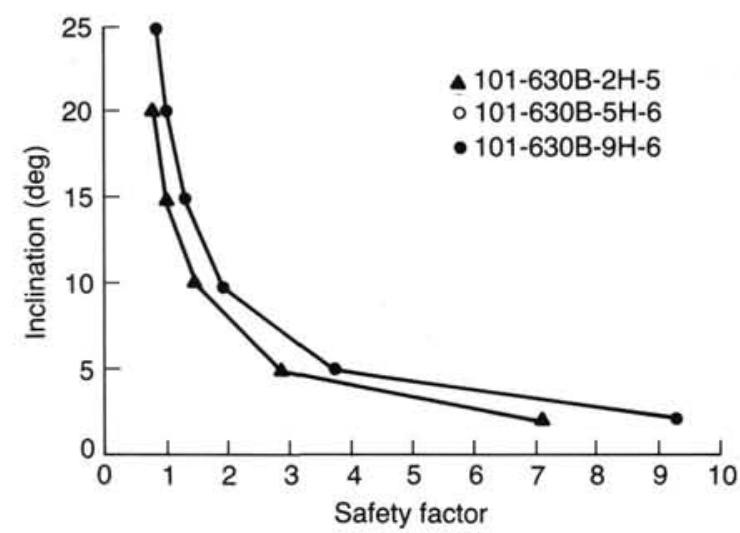

Figure 13. Slope inclination plotted against the safety factor for three intervals at Hole 630B. Sections 101-630B-5H-6 and 101-630B-9H-6 cannot be distinguished, so only one curve is shown (the upper curve); both are stable only to $14^{\circ}$. A safety factor of 1 is the minimum possible before slope failure occurs. a section of sediment sliding downslope north of Little Bahama Bank. The safety factor is further minimized by the fact that sediments at Site 630 are not homogeneous: although scarce and thin, turbidite layers and differing degrees of lithification and total carbonate content within the ooze occur (Austin, Schlager, et al., 1986). Small areas of incipient cementation may contribute further to the lateral and vertical variations in shear strength.

\section{CONCLUSIONS}

1. Sediment sampled at a depth of 10.94 mbsf in Hole 630B unexpectedly displays a lower void ratio, porosity, and water content and a greater cohesiveness than that displayed by sediments recovered from 41 and 79.4 mbsf. This may be a function of a decreasing amount of total calcium carbonate with depth and of the constituents composing that calcium carbonate.

2. The higher permeability displayed at 41 and $79.4 \mathrm{mbsf}$ is a function of effective interparticle fluid flow. The higher percentage of aragonite shallower in the section creates a needlelike, permeable, porous matrix. The matrix material deeper in the section contains more clayey material, which tends to clog pores, but the higher measured permeability appears to be a function of the crushing of foraminifer grains during consolidation. The high intraparticle porosity of the deeper samples does not contribute to permeability until overburden pressure is great enough to crush the grains.

3. Undrained shear strengths and measured shear wave velocities from core samples are lower than expected and display little increase with depth. The samples recovered and tested indicated that sediments are less consolidated than expected. The sediment column may not be consolidating to $250 \mathrm{mbsf}$, but more probably shipboard measurements made on samples from deep in the sediment column are not representative of in-situ undrained shear strengths and shear wave velocities. Instead, shear strength and shear wave velocity of these cohesionless sediments are a function of the effective confining pressure or overburden pressure, which is removed during the coring process. Therefore, shear-strength determinations should be made under in-situ effective stress.

4. Sediments at 10.94 mbsf display a greater cohesiveness and higher angle of internal friction than do sediments sampled deeper in the section, probably a function of both mineralogy and carbonate constituents. The overall consolidated and drained shear strength of all three carbonate samples is low, a fact that should be noted by engineers contemplating operations in a carbonate-slope environment.

5. Assuming a homogeneous sedimentary section to 79.4 mbsf, slope stability calculations indicate that the slope is stable up to a $14^{\circ}$ inclination. However, the presence of inhomogeneities, such as turbidite layers, suggests that the actual stability of the slope may be less than calculated. This is substantiated by abundant seismic evidence of slumping, sliding, and imbricate thrusting on this gentle $\left(2^{\circ}-3^{\circ}\right)$ slope.

\section{ACKNOWLEDGMENTS}

I acknowledge the fine staff of the Ocean Drilling Program and my colleagues, Gregor Eberli, at the Geologisches Institut ETH, Zürich, and Christian Ravenne of the Institut Français du Pétrole, France, for their outstanding efforts during the field phase of this study. I also acknowledge the guidance of Wayne Dunlap of Texas A\&M University, Civil Engineering Department, who allowed me full use of the geotechnical laboratory and equipment for the subsequent shore-based geotechnical analyses, and who reviewed the manuscript. I thank Richard Bennett and Philip Valent, who also reviewed this manuscript and contributed many ideas. The reviews and comments of James Austin, Jr., Amanda Palmer, and Wolfgang Schlager greatly improved this manu- 
script. This project was funded jointly by the USSAC-JOI, and the U.S. Naval Ocean Research and Development Activity, NSTL, Mississippi.

\section{GLOSSARY}

Angle of internal friction ( $\phi)$ : the angle that the failure envelope creates with a horizontal line; $\tan \phi=$ shear strength/normal stress.

Bulk modulus (K): $1 / A_{v}$.

Coefficient of compressibility $\left(A_{v}\right): d e / d \sigma_{v}$, slope of e-log $p$ curve.

Coefficient of consolidation $\left(C_{v}\right)$ : gives an indication of how rapidly or slowly consolidation takes place.

Deviator stress $\left(\sigma_{1}-\sigma_{3}\right)$ : numerical difference between the major $\left(\sigma_{1}\right)$ and minor $\left(\sigma_{3}\right)$ principal stresses.

Effective stress $\left(\sigma^{\prime}\right)$ : total stress $(\sigma)$ - pore water pressure $(\mu)$; intergranular pressure.

Initial void ratio $\left(e_{0}\right)$ : initial void ratio determined after sampling.

Internal friction: particle friction developed by cohesionless soils; property producing most of the shear strength that this type of soil can develop.

Normal stress $\left(\sigma_{n}\right)$ : stress perpendicular to bedding plane.

Permeability $(k)$ : rate of flow past a specified area.

Vertical stress $\left(\sigma_{v}\right)$ : stress perpendicular to a horizontal plane.

Void ratio $(e)$ : ratio of volume of voids to volume of solids.

\section{REFERENCES}

Austin, J. A., Jr., Schlager, W., et al., 1986. Proc. ODP, Init. Repts., 101: College Station, TX (Ocean Drilling Program).

Bathurst, R.G.C., 1976. Carbonate Sediments and Their Diagenesis: New York (Elsevier), 239-243.

Bjerrum, L., 1967. Engineering geology of Norwegian normally consolidated marine clays as related to settlements of buildings. Geotechnique, 17:81-118.

Clukey, E. C., and Silva, A. J., 1981. Permeability of deep-sea clays: Northwestern Atlantic. Mar. Geotechnol., 5:1-25.

Demars, K. R., 1982. Unique engineering properties and compression behavior of deep-sea calcareous sediments. In Demars, K. R., and Chaney, R. C. (Eds.), Geotechnical Properties, Behavior, and Performance of Calcareous Soils: Am. Soc. Test. Mater., ASTM STP $777,97-112$.

Flugel, Erik, 1982, Microfacies Analysis of Limestones: New York (Springer-Verlag).

Folk, R., 1974. Petrology of Sedimentary Rocks: Austin, TX (Hemphill), 33-43.
Hamilton, E., 1980. Geoacoustic modeling of the sea floor. JASA, 68: 1313-1348.

Hodgman, C. D., Weast, R. C., Shankland, R. S., and Selby, S. M., 1963. Handbook of Chemistry and Physics: Cleveland (Chemical Rubber Publishing), 1510-1527.

Keller, G., Lambert, D., and Bennett, R., 1979. Geotechnical properties of continental slope deposits-Cape Hatteras to Hydrographer Canyon. SEPM Spec. Publ., 27:131-151.

Lambe, T. W., and Whitman, R. V., 1979. Soil Mechanics, SI Version: New York (John Wiley), 151-161.

Lambe, W., 1969. Soil Testing for Engineers: New York (John Wiley), 74-87.

Lee, H. J., 1982. Bulk density and shear strength of several deep-sea calcareous sediments. In Demars, K. R., and Chaney, R. C. (Eds.), Geotechnical Properties, Behavior, and Performance of Calcareous Soils: Am. Soc. Test. Mater., ASTM STP 777, 54-78.

Matthews, J. E., 1982. Shear wave velocity measurements on marine sediments. Geo-Mar. Lett., 2:215-218.

Morgenstern, N. R., 1967, Submarine slumping and the initiation of turbidity currents. In Richards, A. (Ed.), Marine Geotechnique: Chicago (Univ. Illinois Press), 189-220.

Müller, G., and Gastner, M., 1971. "The karbonate-bombe," a simple device for determination of the carbonate content in sediments, soils and other materials. N. Jahrb. Mineral. Monatsh., 10:466-469.

Richards, A. F., and Hamilton, E. L., 1967. Investigations of deep-sea sediment cores, III. Consolidation. In Richards, A. (Ed.), Marine Geotechnique: Chicago (Univ. Illinois Press), 93-117.

Skotheim, A., Janbu, N., and Senneset, K., 1985. Determination of effective stress-based shear strength parameters from static and cyclic triaxial tests. In Chaney, R. C., and Demars, K. R. (Eds.), Strength Testing of Marine Sediments: Laboratory and In-situ Measurements: Am. Soc. Test. Mater., ASTM STP 833, 318-335.

Taylor, D. W., 1948. Fundamentals of Soil Mechanics: New York (John Wiley).

Valent, P. J., Altschaeffl, A. G., and Lee, H. J., 1982, Geotechnical properties of two calcareous oozes. In Demars, K. R. and Chaney, R. C. (Eds.), Geotechnical Properties, Behavior, and Performance of Calcareous Soils: Am. Soc. Test. Mater., ASTM STP 777, 79-95.

Date of initial receipt: 14 November 1986

Date of acceptance: 24 August 1987

Ms 101B-151 